\title{
Effects of modification with a combination of styrene-acrylic copolymer dispersion and sodium silicate on the mechanical properties of wood
}

\author{
Thi Tham Nguyen ${ }^{1,2}$, Zefang Xiao ${ }^{1 *}$, Wenbo Che ${ }^{1}$, Hien Mai Trinh ${ }^{2}$ and Yanjun Xie ${ }^{1^{*}}$ (1)
}

\begin{abstract}
Poplar (Populus adenopoda Maxim.) and radiata pine (Pinus radiata Don.) woods were treated with an aqueous solution containing styrene-acrylic copolymer (SAC) dispersion and sodium silicate (SS). The modifying effects on the mechanical properties of wood were investigated with 10\% SAC and varying concentrations of SS. The SAC and the SS deposition occurred in the cell lumina and condensed under catalysis at elevated temperature, as evidenced by scanning electron microscopy. The wood treated with SAC and SS exhibited a moisture content about 2 times higher than that of the untreated control under $95 \%$ relative humidity due to the introduction of hygroscopic silicate. The modulus of rupture (MOR) and modulus of elasticity (MOE) in the bending, compressive strength, surface hardness, tensile strength, and shear strength of the wood were improved up to 83.9, 82.3, 72.7, 48.3, 38.4, and 53.1\%, respectively. However, the impact strength decreased by $39.4 \%$ due to the treatments. Accordingly, the combined treatment with SAC/SS has a potential application in the improvement of the wood quality, but the reduction in impact strength could limit its utilization in products for which high dynamic strength is required.
\end{abstract}

Keywords: Wood treatment, Sodium silicate, Styrene-acrylic copolymer, Moisture content, Mechanical properties

\section{Introduction}

The use of silicon compounds for wood modification has been extensively reported recently [1-6]. Among the silicon compounds, sodium silicate (SS; also known as water glass), a soluble alkaline silicate, has been most commonly used. Sodium silicate can impart wood with improved flame resistance, decay resistance, and dimensional stability $[1,7-10]$. However, sodium silicate is susceptible to leaching from wood during service, thereby resulting in surface contamination. In order to reduce the leaching of silica particles, various resins, such as glyoxal-urea, urea-formaldehyde resin, and melamine

\footnotetext{
*Correspondence: zxiao@nefu.edu.cn; yxie@nefu.edu.cn

${ }^{1}$ Key Laboratory of Bio-based Material Science and Technology (Ministry of Education), College of Material Science and Engineering, Northeast Forestry University, 26 Hexing Road, Harbin 150040, People's Republic of China

Full list of author information is available at the end of the article
}

formaldehyde resin, were used in combination to treat wood [6,11-13], through a process mainly based on the mechanism of physical encapsulation of polymerized resin in wood [10, 14].

Acrylic resins are a known group of thermoplastic or thermosetting plastics, comprising copolymers of functional acrylic monomers and esters of acrylic acid and/ or methacrylic acid, which may also contain monomers with unsaturated vinyl, such as styrene or vinyl toluene [15]. Polymers based on acrylic and methacrylic esters are extensively used in adhesives to consolidate materials such as wood, brick, and stone [16]. The styrene-acrylic copolymer (SAC) is prepared via a batch emulsifier-free emulsion copolymerization of styrene with acrylic acid. The SAC is widely used as the binder in coatings due to its ability to facilitate the improvement of the heat, weathering, and corrosion resistance properties $[4,17$, 
Table 1 Testing items for mechanical properties, specimen size, sample number (replicate), and applied standards

\begin{tabular}{|c|c|c|c|}
\hline Strength property & $\begin{array}{l}\text { Dimension } \\
l \times t \times r^{*} \\
(\mathrm{~mm})\end{array}$ & $\begin{array}{l}\text { Sample } \\
\text { number }\end{array}$ & Standard \\
\hline \multicolumn{4}{|l|}{ Bending } \\
\hline Modulus of rupture (MOR) & $180 \times 10 \times 10$ & 10 & DIN 52186 \\
\hline Modulus of elasticity (MOE) & $180 \times 10 \times 10$ & 10 & DIN 52186 \\
\hline \multicolumn{4}{|l|}{ Compression strength } \\
\hline Longitudinal direction & $30 \times 20 \times 20$ & 10 & DIN 52185 \\
\hline Radial direction & $30 \times 20 \times 20$ & 10 & DIN 52185 \\
\hline Surface hardness & $40 \times 30 \times 30$ & 10 & ASTM D2240 \\
\hline Impact bending strength (IBS) & $80 \times 10 \times 4$ & 10 & $\mathrm{~GB} / \mathrm{T} 1940$ \\
\hline $\begin{array}{l}\text { Tensile strength parallel to the } \\
\text { grain }\end{array}$ & $370 \times 20 \times 15$ & 10 & GB/T 1938 \\
\hline $\begin{array}{l}\text { Shear strength parallel to the } \\
\text { grain }\end{array}$ & $35 \times 20 \times 40$ & 10 & GB/T 1937 \\
\hline
\end{tabular}

18]. The SAC has also been used as a modifying agent to treat wood to improve wood quality [19].

Previously, we have studied the flame-retardant performance of poplar (Populus adenopoda Maxim.) and radiata pine (Pinus radiata Don.) woods treated with SAC and sodium silicates. The findings indicated that combined treatment with SAC and SS made it more difficult to ignite these woods, as evidenced by the longer ignition time and higher limiting oxygen index. As a biomass material, the mechanical properties of the treated wood have not yet been reported.

The main objective of this study was to further investigate the effect of the treatment with the combined SAC and SS on the mechanical properties of poplar and radiata pine woods, which are fast-growing wood species extensively used in the wood industry. The moisture content $(\mathrm{MC})$ of untreated and treated wood is also investigated. Additionally, the local distribution of chemicals in the wood is examined by scanning electron microscopy (SEM).

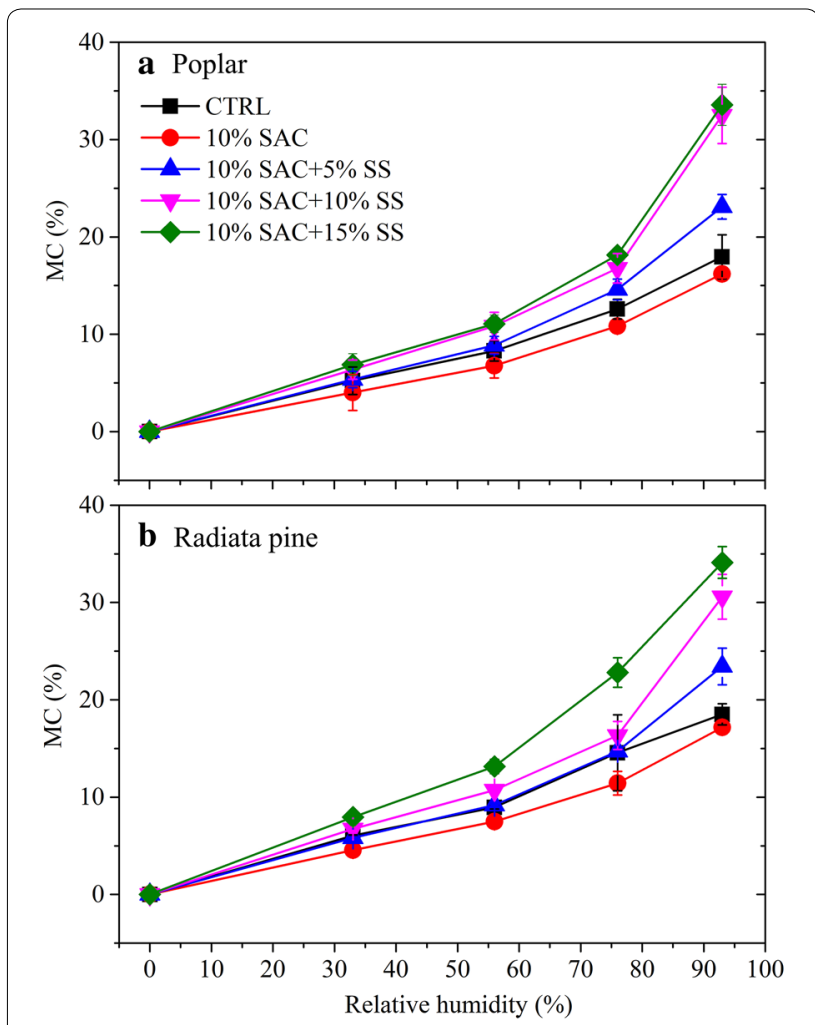

Fig. 1 Moisture content (MC) of poplar (a) and radiata pine (b) untreated and treated with 10\% SAC plus varying concentrations of SS, respectively. Error bars show StD based on 15 replicates

\section{Materials and methods \\ Materials}

The treated woods were poplar (Populus adenopoda Maxim.) and radiata pine (Pinus radiata Don.) sapwoods (oven-dried density of approx. $530 \mathrm{~kg} \mathrm{~m}^{-3}$ and $410 \mathrm{~kg} \mathrm{~m}^{-3}$, respectively), originated in China and New Zealand, respectively. Wood specimens measuring $10 \mathrm{~mm}$ (longitudinal) $\times 20 \mathrm{~mm}$ (tangential) $\times 20 \mathrm{~mm}$ (radial) were used to determine the weight percent gain (WPG) and MC. A summarized overview of the size,

Table 2 The density of poplar and radiata pine wood before and after treatment with $10 \%$ SAC plus varying concentrations of SS (15 replicates for each treatment)

\begin{tabular}{|c|c|c|c|c|}
\hline \multirow[t]{3}{*}{ Treatment } & \multicolumn{4}{|l|}{ Density $\left(\mathrm{kg} \mathrm{m}^{-3}\right)$} \\
\hline & \multicolumn{2}{|l|}{ Poplar } & \multicolumn{2}{|l|}{ Radiata pine } \\
\hline & Before treatment & After treatment & Before treatment & After treatment \\
\hline $10 \% \mathrm{SAC}$ & $528.51(29.64)$ & 603.34 (20.93) & $407.22(57.37)$ & $466.42(28.45)$ \\
\hline $10 \% \mathrm{SAC}+5 \% \mathrm{SS}$ & $524.62(19.98)$ & $626.49(28.27)$ & $410.66(42.53)$ & $482.63(32.01)$ \\
\hline $10 \% \mathrm{SAC}+10 \% \mathrm{SS}$ & $530.70(42.72)$ & $632.10(35.02)$ & $412.82(36.72)$ & $513.68(46.15)$ \\
\hline $10 \% \mathrm{SAC}+15 \% \mathrm{SS}$ & $527.59(58.49)$ & $646.69(29.46)$ & $410.21(50.61)$ & 521.57 (36.70) \\
\hline
\end{tabular}

Data in parentheses show the standard deviation 
specimen replicate and standards for the mechanical testing is shown in Table 1 . The MC of all specimens was conditioned to $10-12 \%$ before treatment.

The SAC dispersion was obtained from Diransa San Luis S.A (Buenos Aires, Argentina). The SAC dispersion had a solid content of $33 \%, \mathrm{pH} 8.46$, and an average molecular mass of $15,000 \mathrm{~g} \mathrm{~mol}^{-1}$. The SS with a silica/ alkali molar ratio of 1.03/1.0 was purchased from Fuchen Chemical Reagent Factory (Tianjin, China). The polycarbodiimide crosslinking agent was of extra purity grade and obtained from Xirun Chemical Technology Co., Ltd. (Shanghai, China).

\section{Modification of the wood}

Wood specimens were oven dried at $103{ }^{\circ} \mathrm{C}$ for $24 \mathrm{~h}$, and the dry weight was determined thereafter $\left(W_{1}\right)$. The specimens were fully impregnated in aqueous solutions under vacuum $(0.01 \mathrm{MPa}, 12 \mathrm{~h})$, followed by pressurization with compressed air (0.6 $\mathrm{MPa}$, $48 \mathrm{~h})$. The aqueous solutions contained $10 \%$ SAC plus $0,5,10$, or $15 \%$ SS (based on the total weight of the solution). In addition, $10 \%$ of the polycarbodiimide crosslinking agent (based on the weight of SAC) was added to each solution to serve as a catalyst to readily form a polymeric network. The specimens were designated as $W_{10} \% \mathrm{SAC}, W_{10} \% \mathrm{SAC}+5 \% \mathrm{SS}, W_{10} \% \mathrm{SAC}+10 \% \mathrm{SS}$, $W_{10} \% \mathrm{SAC}+15 \% \mathrm{SS}$, respectively. After impregnation, the specimens were dried in air at room temperature for 1 week to a MC of approximately $20-25 \%$. Afterward, the specimens were cured at $80^{\circ} \mathrm{C}$ for $24 \mathrm{~h}$ and then at $110{ }^{\circ} \mathrm{C}$ for $24 \mathrm{~h}$. The dried specimens were weighed $\left(W_{2}\right)$. Untreated specimens $\left(W_{\text {CTRL }}\right)$ were used as control. Ten replicate specimens were used per treatment. The WPG of the treated wood was from 15 to $25 \%$. The density of the wood before and after treatment was also determined (Table 2).

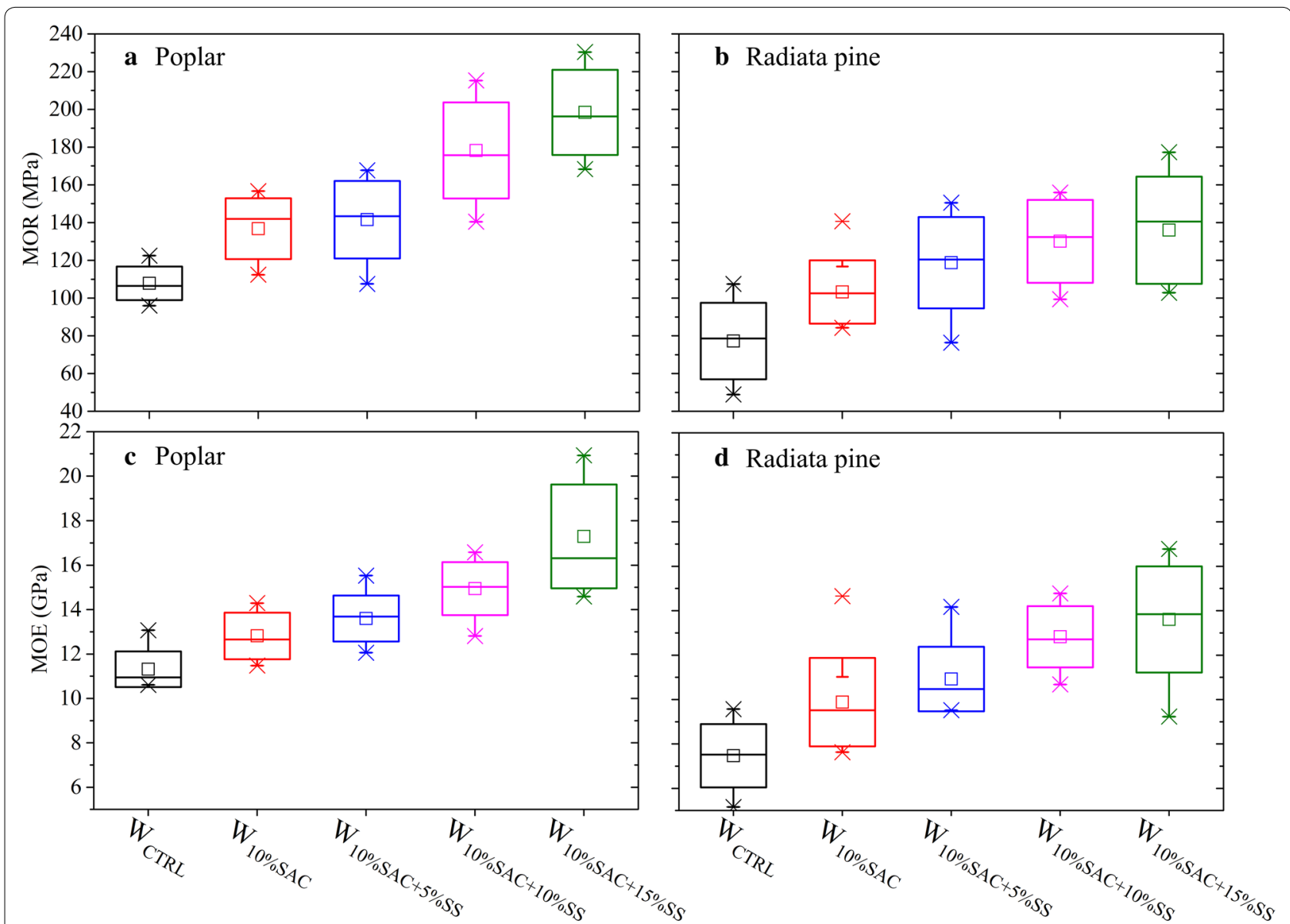

Fig. 2 Modulus of rupture (MOR) and modulus of elasticity (MOE) in bending of poplar $(\mathbf{a}, \mathbf{c})$ and radiata pine (b, d) untreated and treated with $10 \%$ SAC and varying concentrations of SS, respectively. The labels shown in the $x$-coordinate: $W=$ wood sample, CTRL $=$ untreated control, SAC means styrene-acrylic copolymer and SS is sodium silicate. The bottom and top edges of the box are standard deviation, the band in the box is 50th percentile, $x$-symbol at the end of box chart represents the 1st percentile (bottom end) and the 99th percentile (top end), the small square in the box represents the mean, and the whiskers out of box chart represent the outliers 


\section{Moisture content (MC)}

The untreated and treated wood specimens were kept in a desiccator and equilibrated at $33,56,76$, and $93 \%$ relative humidity $(\mathrm{RH})$ above saturated salt solutions at room temperature $\left(\sim 22^{\circ} \mathrm{C}\right)[20,21]$. At specific $\mathrm{RH}$, the specimens were conditioned for 4 weeks and the total test was performed in 16 weeks. After conditioning at each $\mathrm{RH}$, the specimen was weighed and the $M C$ was calculated according to Eq. (1):

$$
M C(\%)=\frac{m_{2}-m_{1}}{m_{1}}
$$

where $m_{2}$ is the weight of untreated or treated wood specimen after conditioning at a given $\mathrm{RH}$ for 4 weeks, and $m_{1}$ is the oven dried weight of wood specimen before conditioning. Fifteen replicates were used for each group in the experiments.

\section{Mechanical property testing}

The bending properties, modulus of rupture (MOR) and modulus of elasticity (MOE) in a three-point bending were determined at a test speed of $1.5 \mathrm{~mm} \mathrm{~min}^{-1}$ according to DIN 52186 (1978) with an electromechanical universal testing machine (MTS Systems Co., Ltd., Shanghai, China). The compression tests, for the longitudinal direction and radial direction, were conducted at a test speed of $0.9 \mathrm{~mm} \mathrm{~min}^{-1}$ on the same machine according to DIN 52185. The tensile strength and shear strength parallel to the grain of the wood were also determined on the same machine as indicated above according to GB/T 1938 (2009) and GB/T 1937 (2009), respectively. The impact bending strength was determined using a speed of $3.8 \mathrm{~m} \mathrm{~s}^{-1}$ with a $15 \mathrm{~J}$ pendulum according to the modified standard GB/T 1940 (2009) with an XJC-25 Combined Charpy and Izod Pendulum Impact Tester (Drick Instruments Co., Ltd., Shandong, China). Surface hardness was measured with a Time TH210 Hardness Tester (Beijing TIME High Technology Ltd., Beijing, China) with
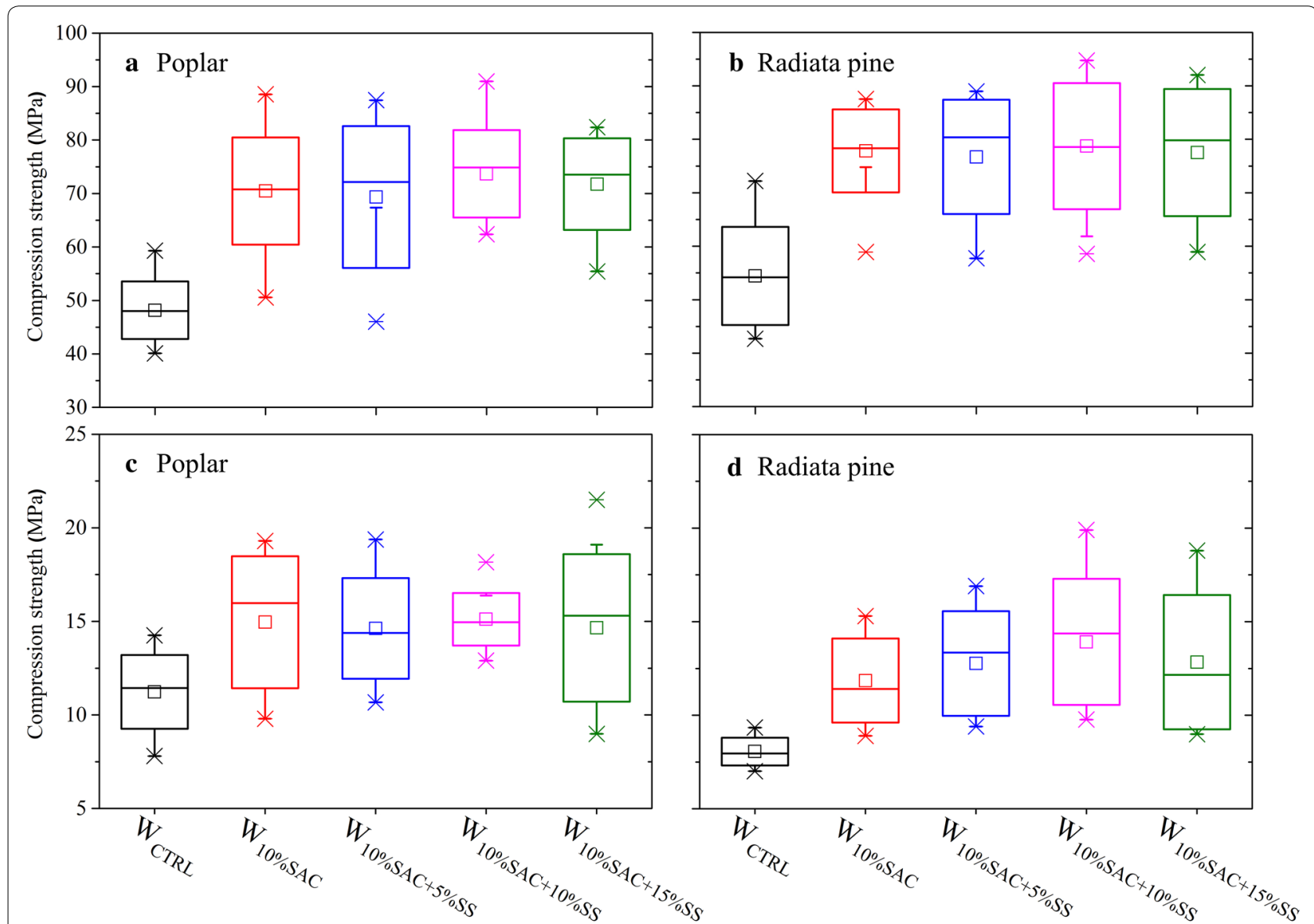

Fig. 3 Compression strength in the longitudinal $(\mathbf{a}, \mathbf{b})$ and radial direction $(\mathbf{c}, \mathbf{d})$ of poplar $(\mathbf{a}, \mathbf{c})$ and radiata pine $(\mathbf{b}, \mathbf{d})$ untreated and treated with 10\% SAC and varying concentrations of SS, respectively. The labels in the $x$-coordinate and the meaning of box chart are same as Fig. 2 
an integrated probe and expressed as Shore D hardness according to the ASTM D2240 method. Before testing, the specimens were conditioned at $20^{\circ} \mathrm{C}$ and $65 \% \mathrm{RH}$.

\section{Fractured surface examination}

The camera and SEM were used to examine the morphological details of the fractured surface of the untreated and treated wood samples after the bending test. Before microscopic observations, all samples were dried and sputtered with gold and then observed on a scanning electron microscope (FEI Quanta 200 SEM, Holland) at an acceleration voltage of $5-10 \mathrm{kV}$.

\section{Results and discussion}

\section{Moisture content}

With the stepwise increase in $\mathrm{RH}$, the adsorption curves of the untreated and treated wood showed the typical adsorption curves of cellulosic materials (Fig. 1).
Although the $\mathrm{MC}$ at a certain $\mathrm{RH}$ varies between poplar and radiata pine wood, the sigmoidal shape of the sorption isotherm is similar for both wood species. The MC increases almost linearly in the lower $\mathrm{RH}$ region (below $60 \%$ ), while the $\mathrm{MC}$ increases rapidly with $\mathrm{RH}$ above $60 \%$. In addition, the results revealed that the MC of the SAC-treated specimens slightly decreases compared with the $W_{\mathrm{CTRL}}$. The small decrease in the $\mathrm{MC}$ is due to the base-catalyzed degradation of the hygroscopic hemicelluloses and the physical barrier of the SAC inclusions in the cell lumina $[19,22]$. The deposited SAC blocked the pit connecting the two wood cells, thus preventing the migration of moisture in the wood cell through the pit. However, the MC of SAC/SS-treated wood specimens significantly increased with increasing SS concentration. This can be explained by the hygroscopic nature of the sodium silicate $[1,23]$, which leads to an increased hygroscopicity in the whole wood matrix. Therefore, the combination of SAC/SS had no effect on improving the moisture excluding efficiency of wood. Thus, the treated

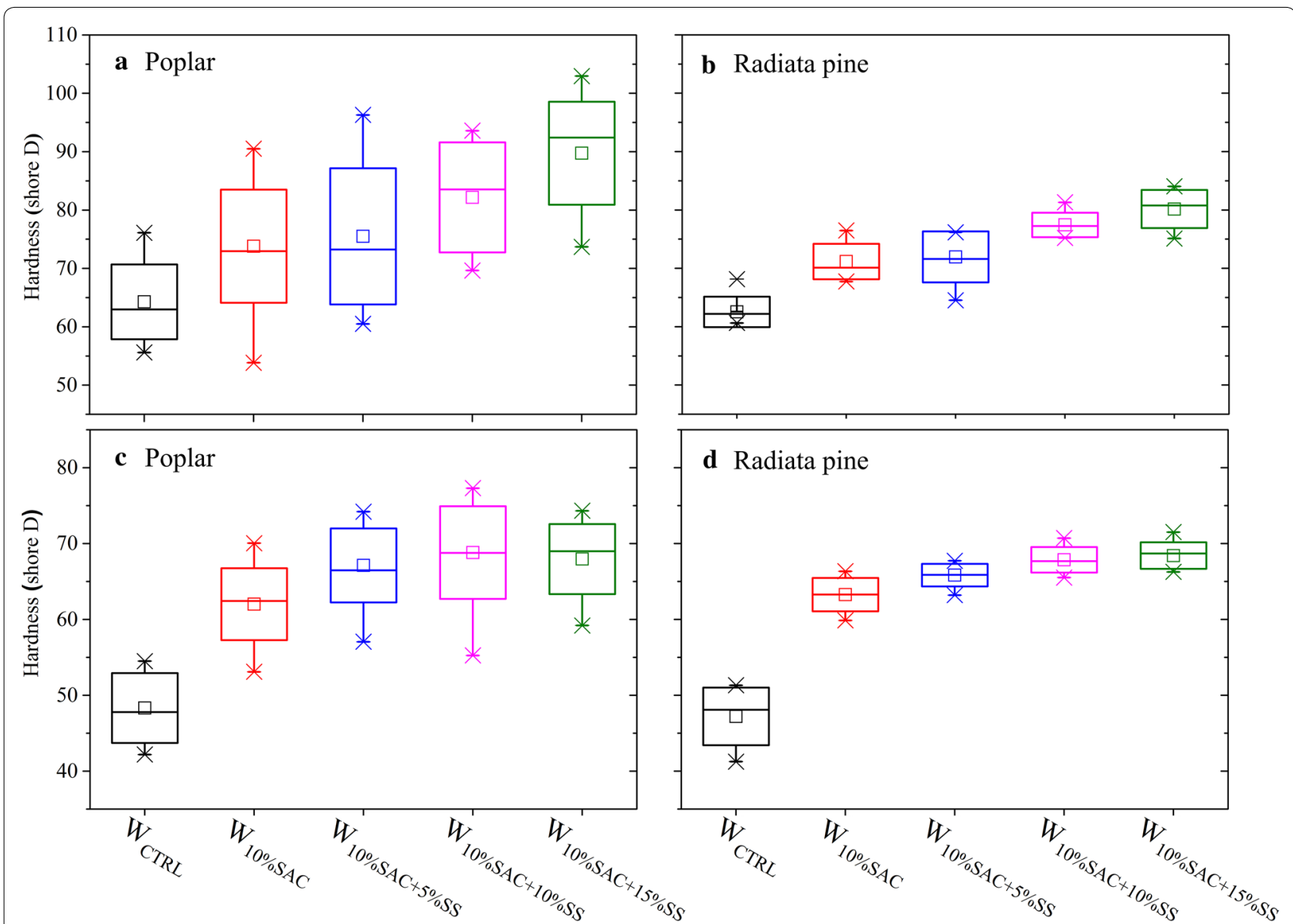

Fig. 4 Surface hardness of cross-section and radial section of poplar $(\mathbf{a}, \mathbf{c})$ and radiata pine $(\mathbf{b}, \mathbf{d})$ untreated and treated with 10\% SAC and varying concentrations of SS, respectively. The labels in the x-coordinate and the meaning of box chart are same as Fig. 2 
wood is recommended for use indoors and in low humidity conditions.

\section{Bending properties}

The MOR and MOE of treated woods were increased after the combined treatment with SAC and SS (Fig. 2). The $W_{10} \% \mathrm{SAC}+15 \% \mathrm{SS}$ specimen exhibited the highest MOR and MOE values among the poplar and radiata pine woods. Compared to the untreated wood, the $W_{10 \% \text { SAC }+15 \text { sS }}$ specimen of poplar wood had an MOR and MOE of 83.9 and $52.8 \%$, respectively, higher than those of the $W_{\text {CTRL }}$ specimen (Fig. 2a, c). The radiata pine wood treated with $10 \%$ SAC and 15\% SS also had a MOR and MOE of 76.0 and $82.3 \%$ higher, respectively, than those of the $W_{\text {CTRL }}$ (Fig. 2b, d). These improvements may be due to the reinforcement effect of the SAC inclusions and the SS depositions into the cell lumina. The stiff inclusions share the applied load with the cell walls through the interfaces [19]. The same principle leads to the increase of the compressive strength and surface hardness [24].

\section{Compression strength}

The compression strength in the longitudinal and radial direction of the poplar and radiata pine woods after treatment is shown in Fig. 3. Treatments with SAC plus different concentrations of SS caused a significant increase in the compression strength of up to 52.9 and $44.6 \%$ in the longitudinal direction of poplar wood (Fig. 3a) and radiata pine wood (Fig. 3b), respectively. Similarly, the transversal compression strength in the radial direction of both wood species also showed a significant increase of up to 38.1 and $72.7 \%$ (Fig. 3c, d), respectively. This may be due to the increased density after each treatment. Specimens treated with the combined systems are stiffer and have larger WPG. Thus, the increases are higher than those of the SAC-treated specimens. Also, the SAC and SS are deposited on the wood cell lumina, coated on the walls around the microfibrils, and formed a physical binding with the wood, so that the relative freedom of the microfibrils decreased, and the rigidity increased, which improved the strength of the cell wall. Ultimately, the ability of the tested material to withstand the external pressure was enhanced and led to a more significant increase in the compression strength.

\section{Surface hardness}

After the modification, the surface hardness of the poplar and radiata pine significantly increased in both the crosssection and radial section (Fig. 4). The hardness of the wood gradually increased with the increase of the concentration of SS incorporated into the 10\% SAC for wood treatment.

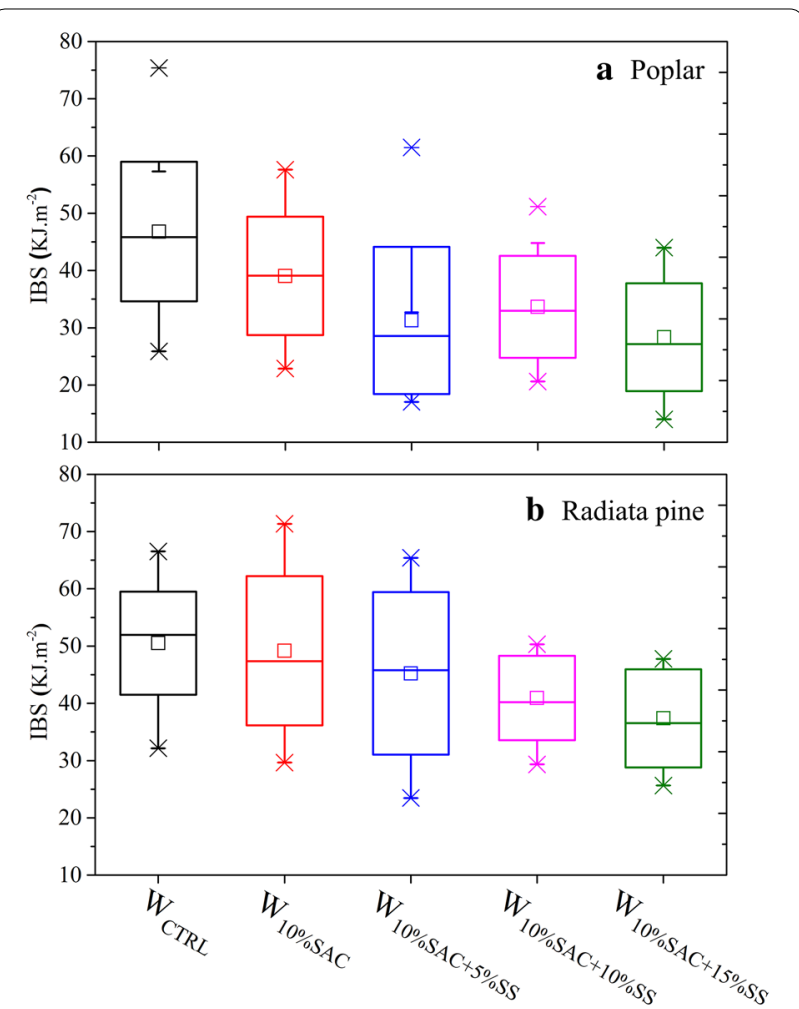

Fig. 5 Impact bending strength (IBS) of poplar (a) and radiata pine (b) untreated and treated with $10 \%$ SAC and varying concentrations of SS. The labels in the $x$-coordinate and the meaning of box chart are same as Fig. 2

The hardness value for the $W_{10} \% \mathrm{SAC}+15 \% \mathrm{sS}$ specimen was 39.6 and $48.3 \%$ higher than those of the untreated poplar cross-section (Fig. 4a) and radial section (Fig. 4c), respectively. Similarly, the $W_{10 \% \mathrm{SAC}+15 \% \mathrm{SS}}$ specimen of radiata pine showed 28.2 and $44.9 \%$ higher hardness value than those of the untreated cross-section (Fig. 4b) and radial section (Fig. 4d), respectively. The enhanced hardness of the treated wood can probably be attributed to the SAC (partially crosslinked with the polycarbodiimide crosslinking agent), which can stiffen the wood matrix, and the stiffness of its inclusions in the cell lumina [25]. Additionally, as the SS was dispersed in the SAC and impregnated into the wood under pressure, it may be retained in the SAC or deposited in the wood cell lumina and subsequently polymerizes, thereby increasing the wood's hardness (as indicated above) and allowing better load transfer.

\section{Impact bending strength}

Treatment with $10 \%$ SAC caused $16.6 \%$ reduction in the impact bending strength (IBS) of the poplar wood, but did not substantially influence the IBS of radiata pine 
wood (Fig. 5). The samples treated with the combined SAC/SS exhibited further decrease in impact bending strength with increasing SS concentration. Specifically, the treated poplar wood exhibited a reduction of up to $39.4 \%$, and the treated radiata pine wood was $26.0 \%$ after treatment with $10 \%$ SAC and $15 \%$ SS. The reduction in the IBS was attributed to the hydrolysis or degradation of the cell wall polysaccharides (mainly hemicellulose) at high $\mathrm{pH}$ and high temperature conditions during the curing process [26]. A decreased impact strength of the test materials indicates that the brittleness is increased and thus the treated wood is not suitable for use as load-bearing materials.

\section{Tensile strength and shear strength}

The tensile strength and shear strength parallel to the grain of the treated and untreated wood specimens are presented in Fig. 6. These results revealed that treatment of the wood with SAC resulted in an improvement in both the tensile strength and shear strength.
These strengths also increased drastically when SS was added due to the reinforcement effect of the SACSS inclusions in the cell lumina, which was similar to its bending behavior. At the highest SS concentration (15\%), the tensile strength of the modified poplar and radiata pine wood specimens was increased by about 38.4 and $38.3 \%$, respectively (Fig. 6a, b), while their shear strength was increased by about 53.1 and $41.4 \%$, respectively (Fig. 6c, d).

\section{Fractured morphology analysis}

The fracture morphology of the untreated and treated woods after the bending tests is shown in Fig. 7. The untreated wood exhibited an irregular fracture surface with jagged breakage line (Fig. 7a, b), which is similar to the findings reported by Xie et al. [27]. This suggests that both the untreated poplar and pine woods are tough. The fracture morphology of the 10\% SAC-treated poplar wood was comparable to that of the untreated poplar wood (Fig. 7c). Compared to the 10\% SAC-treated poplar wood, the radiata pine treated with $10 \%$ SAC exhibited
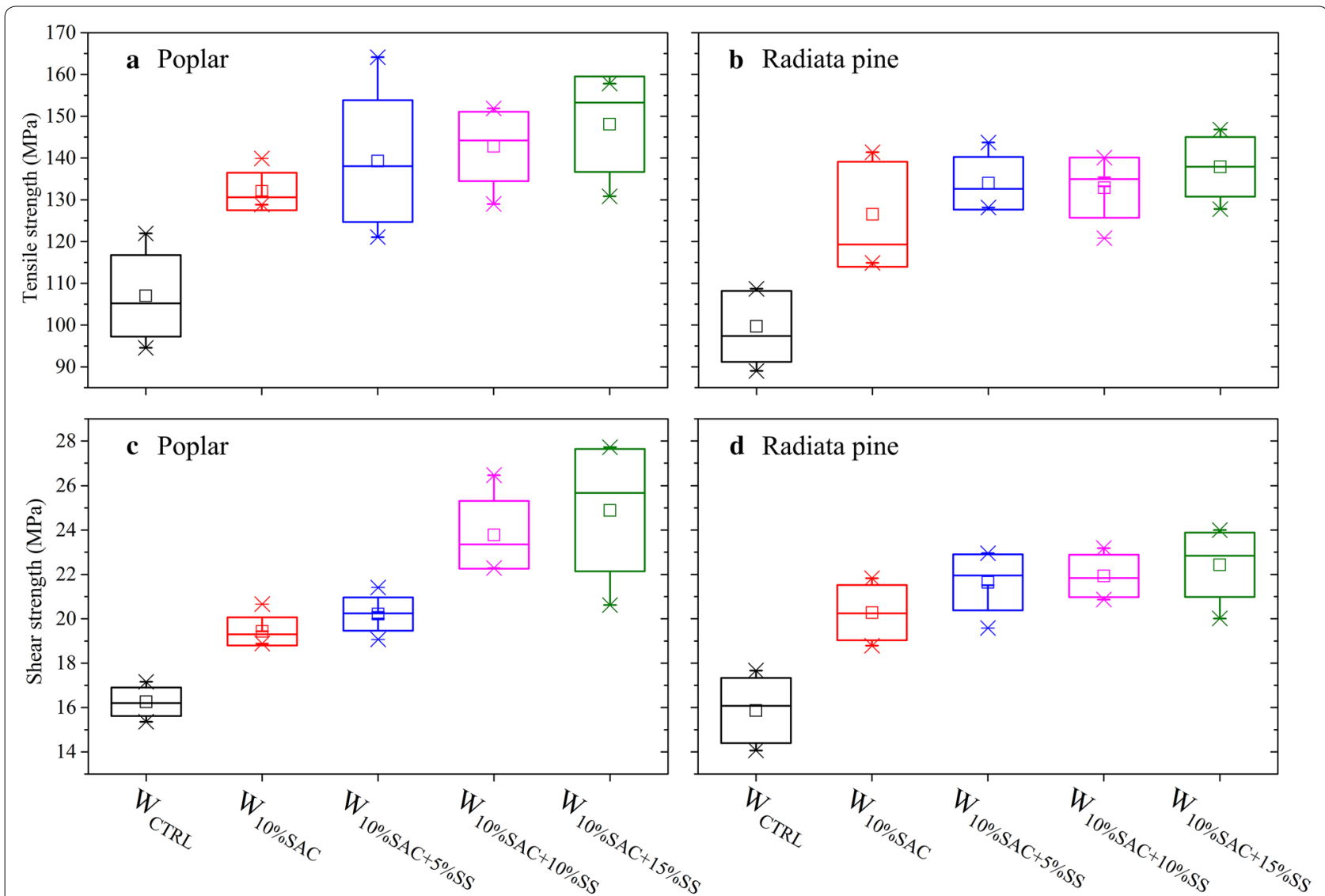

Fig. 6 Tensile strength and shear strength parallel to the grain of poplar $(\mathbf{a}, \mathbf{c})$ and radiata pine $(\mathbf{b}, \mathbf{d})$ untreated and treated with $10 \%$ SAC and varying concentrations of SS, respectively. The labels in the x-coordinate and the meaning of box chart are same as Fig. 2 

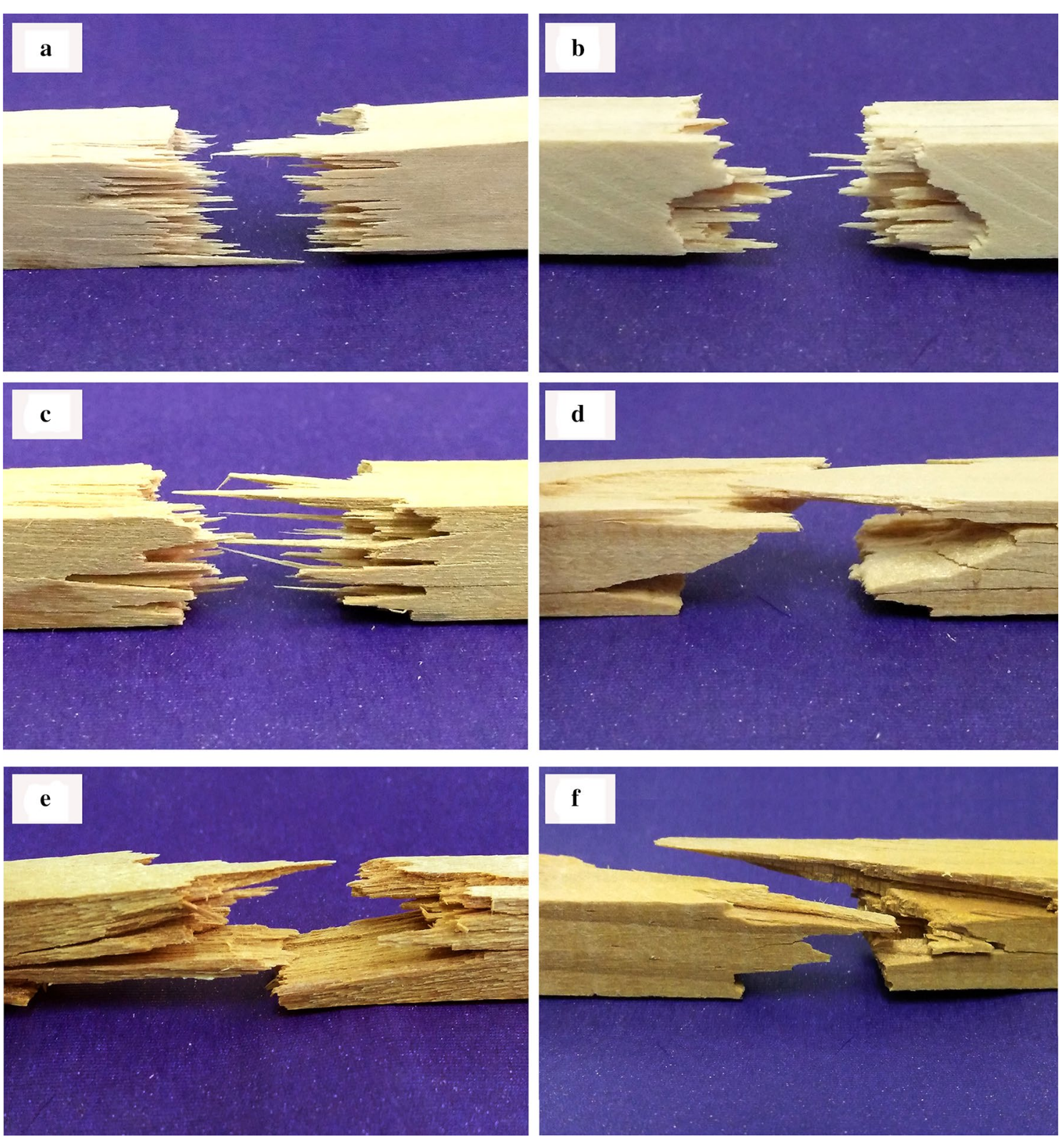

Fig. 7 Typical fracture modes of poplar $(\mathbf{a}, \mathbf{c}, \mathbf{e})$ and radiata pine $(\mathbf{b}, \mathbf{d}, \mathbf{f})$ untreated and treated with 10\% SAC, and 10\% SAC+15\% SS, respectively, after the bending test

less toughness, which is attributed to larger cell lumen and thinner cell walls of the former (Fig. 7d). The fractured surface of wood treated with SAC and various concentrations of SS still showed a jagged but less scraggly breakage (Fig. 7e, f), implying a slight embrittlement. The brittle fractured profile is consistent to the decreased impact bending strength (Fig. 5).

\section{Scanning electron microscopic (SEM) analysis}

The images of the fractured surfaces of the tested wood samples examined by SEM are displayed in Fig. 8. The SEM image of the fractured surfaces of the untreated wood shows hollow cell lumina and broken microfibrils (Fig. 8a, b). No deposition of chemicals was observed in the cell lumina. After treatment with $10 \%$ SAC, the SAC deposited in the cell lumina, forming the tubular-shaped or cylindrical-shaped inclusions after polymerization (Fig. 8c, d), which may thicken the cell wall, which may 

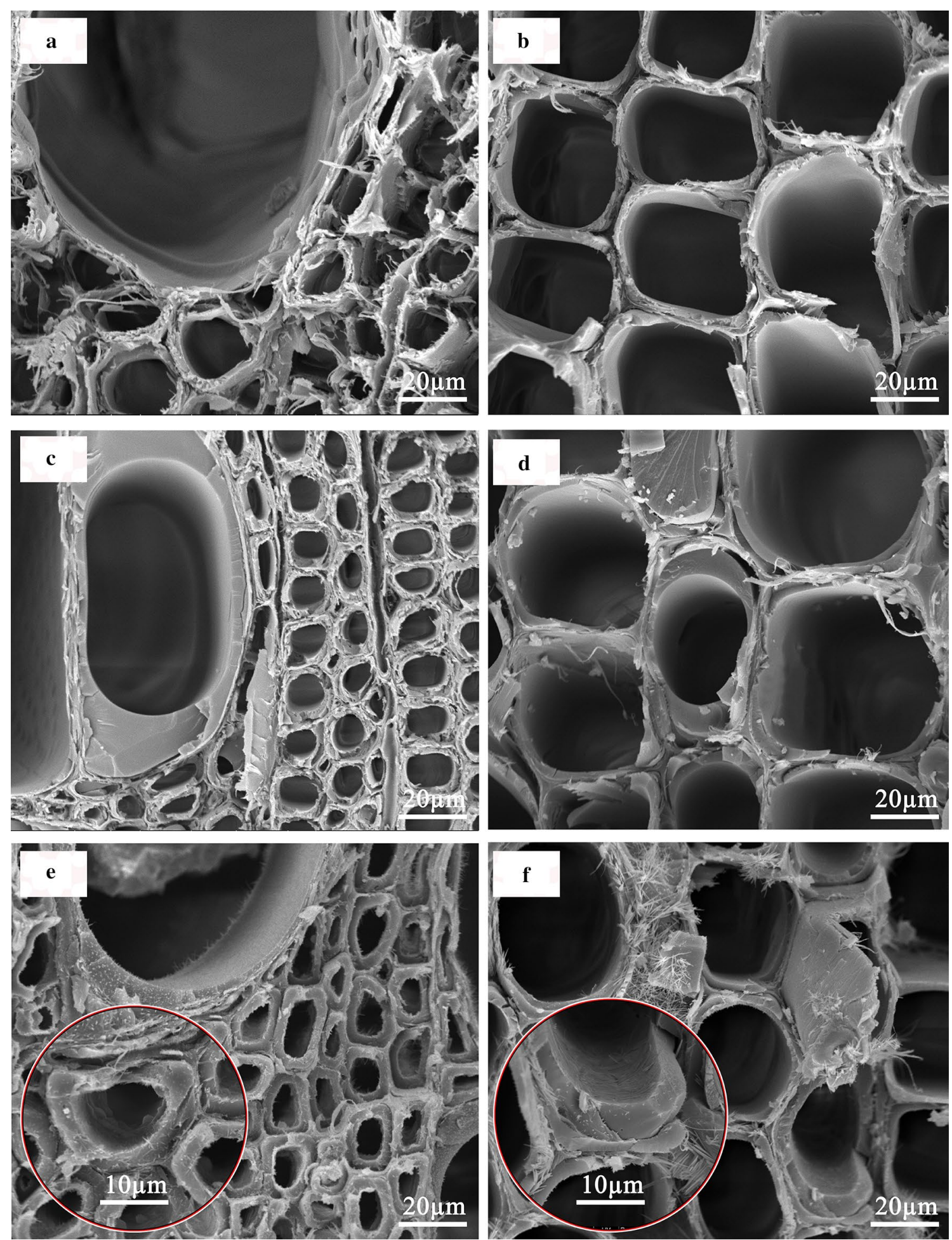

Fig. 8 Micrographic features of the flexure samples of poplar [a, $\mathbf{c}, \mathbf{e}$, cross-section $(\times 1000)]$ and radiata pine $[\mathbf{b}, \mathbf{d}, \mathbf{f}$, cross-section $(\times 1000)]$ untreated and treated with 10\% SAC and 10\% SAC + 15\% SS, respectively, after the bending test 
mechanically strengthen the cell walls [28]. Combinative treatments with SAC and SS caused different fractured profile of woods (Fig. 8e, f). Many needle-like rods were found to imbed in the SAC polymeric inclusion. These rods should be the silica formed from condensation of the hydrolyzed SS. They may further strengthen the inclusions as a hybrid body.

Notably, the cell walls of the treated poplar wood exhibited an increased deformation and shrinking (Fig. 8e) with increasing SS concentration (not shown). This phenomenon can be explained by the partial dissolution of hemicellulose from the cell wall during treatment in the alkaline solution. In contrast, the treated pine wood did not shrink and the cell shape was similar to that of the untreated wood (Fig. 8f).

\section{Conclusion}

This study investigated the effect of the treatment with SAC dispersion and SS on the mechanical properties of poplar wood and radiata pine wood. The results showed that the treatment of these woods with combined SAC and SS resulted in an increase in the MC and the results suggested that the treated wood may be used indoors. The MOR and MOE of wood bending, compression strength, surface hardness, tensile strength and shear strength of the treated wood were improved due to the incorporation of the polymeric SAC inclusions and the needle-like silica rods in the cell lumina. The improved mechanical properties contribute to raise the quality of fast-growing wood species and thus enhance their added values. The impact strength was decreased up to $39.4 \%$ due to the hydrolysis of the cell wall polysaccharides at high $\mathrm{pH}$ and temperature during the curing process, which may limit the use of the treated wood as a load-bearing material. The results of this study demonstrate the feasibility of the treatment of wood with combined SAC and SS. The wood is suitable for use in the indoor domains, such as flooring and furniture. However, other critical properties of the wood after modification with combined SAC and SS, such as its fungal decay resistance, weathering, and deformation/shrinking of the wood (such as poplar wood) need to be further investigated.

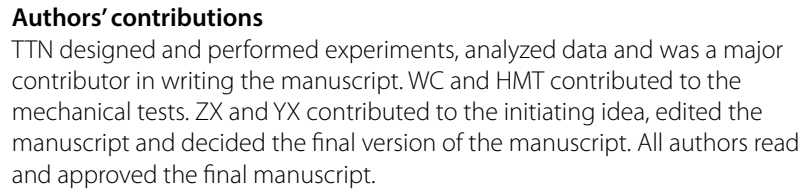

\section{Author details}

${ }^{1}$ Key Laboratory of Bio-based Material Science and Technology (Ministry of Education), College of Material Science and Engineering, Northeast Forestry University, 26 Hexing Road, Harbin 150040, People's Republic of China. ${ }^{2}$ Wood Industry College, Vietnam National University of Forestry, Xuan Mai, Chuong My, Hanoi 10000, Vietnam.

\section{Acknowledgements}

This work was supported by the National Key Research and Development Program of China (2017YFD0600203), the National Natural Science Foundation of China (31470585 \& 31500469).

\section{Competing interests}

The authors declare that they have no competing interests.

\section{Availability of data and materials}

The authors will not share original data because of personal interests, such as patents or potential future studies.

\section{Funding}

(1) The National Key Research and Development Program of China (2017YFD0600203). (2) The National Natural Science Foundation of China (31470585). (3) The National Natural Science Foundation of China (31500469).

\section{Publisher's Note}

Springer Nature remains neutral with regard to jurisdictional claims in published maps and institutional affiliations.

Received: 1 October 2018 Accepted: 11 December 2018

Published online: 08 February 2019

\section{References}

1. Furuno T, Shimada K, Uehara T, Jodai S (1992) Combination of wood and silicate, 2: wood-mineral composites using water glass and reactants of barium chloride, boric acid, and borax, and their properties. J Jap Wood Res Soc 38(5):448-457

2. Böttcher H, Jagota C, Trepte J, Kallies KH, Haufe H (1999) Sol-gel composite films with controlled release of biocides. J Control Release 60(1):57-65

3. Mai C, Militz H (2004) Modification of wood with silicon compounds. Treatment systems based on organic silicon compounds_-a review. Wood Sci Technol 37(6):453-461

4. Fan F, Xia Z, Li Q, Li Z, Chen H (2013) Thermal stability of phosphorus-containing styrene-acrylic copolymer and its fire retardant performance in waterborne intumescent coatings. J Therm Anal Calorim 114(3):937-946

5. Xiao Z, Xu J, Mai C, Militz H, Wang Q, Xie Y (2016) Combustion behavior of Scots pine (Pinus sylvestris $\mathrm{L}$.) sapwood treated with a dispersion of aluminum oxychloride-modified silica. Holzforschung 70(12):1165-1173

6. Dong Y, Yan Y, Zhang S, Li J, Wang J (2015) Flammability and physicalmechanical properties assessment of wood treated with furfuryl alcohol and nano-SiO 2 . Eur J Wood Wood Prod 73(4):457-464

7. Furuno T, Uehara T, Jodai S (1993) Combinations of wood and silicate, 3 : some properties of wood-mineral composites using the water glassboron compound system. J Jap Wood Res Soc 39(5):561-570

8. Šimkovic I, Martvonová H, Maníková D, Grexa O (2005) Flame retardance of insolubilized silica inside of wood material. J Appl Polym Sci 97(5):1948-1952

9. Slimak KM, Slimak RA (2007) Process of using sodium silicate to create fire retardant products. US Patent 7,297.411 B2. 20 Nov 2007

10. Pereyra AM, Giudice CA (2009) Flame-retardant impregnants for woods based on alkaline silicates. Fire Safety J 44(4):497-503

11. Hazarika A, Maji TK (2014) Properties of softwood polymer composites impregnated with nanoparticles and melamine formaldehyde furfuryl alcohol copolymer. Polym Eng Sci 54(5):1019-1029

12. Yan Y, Dong Y, Li J, Zhang S, Xia C, Shi SQ, Cai L (2015) Enhancement of mechanical and thermal properties of Poplar through the treatment of glyoxal-urea/nano- $\mathrm{SiO}_{2}$. RSC Adv 5(67):54148-54155

13. Shi J, Li J, Zhou W, Zhang D (2007) Improvement of wood properties by urea-formaldehyde resin and nano-SiO 2 . Front For China 2(1):104-109

14. Jiang T, Feng X, Wang Q, Xiao Z, Wang F, Xie Y (2014) Fire performance of oak wood modified with $\mathrm{N}$-methylol resin and methylolated guanylurea phosphate/boric acid-based fire retardant. Constr Build Mater 72:1-6

15. Tilak G (1985) Thermosetting acrylic resins-a literature review. Prog Org Coat 13(5):333-345

16. Chiantore O, Lazzari M (1996) Characterization of acrylic resins. Int J Polym Anal Ch 2(4):395-408 
17. Chuang CS, Tsai KC, Wang MK, Ko CH, Ing-Luen S (2009) Impact of the intumescent formulation of styrene acrylic-based coatings on the fire performance of thin painted red lauan (Parashorea spp.) plywood. Eur J Wood Wood Prod 67(4):407-415

18. Zhong Z, Yu Q, Yao H, Wu W, Feng W, Yu L, Xu Z (2013) Study of the styrene-acrylic emulsion modified by hydroxyl-phosphate ester and its stoving varnish. Prog Org Coat 76(5):858-862

19. Che W, Xiao Z, Han G, Zheng Z, Xie Y (2018) Radiata pine wood treatment with a dispersion of aqueous styrene/acrylic acid copolymer. Holzforschung 72(5):387-397

20. Siau JF (1984) Basic wood-moisture relationships. Transport processes in wood. Springer, Berlin, pp 1-34

21. Gezici-Koç Ö, Erich SJ, Huinink HP, van der Ven LG, Adan OC (2017) Bound and free water distribution in wood during water uptake and drying as measured by 1D magnetic resonance imaging. Cellulose 24(2):535-553

22. Alma M, Maldas D, Hafizo H (1995) Water repellency of several wood species impregnated with vinyl monomers. Int J Polym Mater 30(3-4):159-165
23. Kartal SN, Hwang WJ, Yamamoto A, Tanaka M, Matsumura K, Imamura Y (2007) Wood modification with a commercial silicon emulsion: effects on boron release and decay and termite resistance. Int Biodeter Biodegr 60(3):189-196

24. Rowell RM (2012) Handbook of wood chemistry and wood composites. CRC Press, London

25. Gind I W, Hansmann C, Gierlinger N, Schwanninger M, Hinterstoisser B, Jeronimidis G (2004) Using a water-soluble melamine-formaldehyde resin to improve the hardness of Norway spruce wood. J Appl Polym Sci 93(4):1900-1907

26. Matthes R, Nehring H, Dellith W (2002) Wasserglas-Holzschutz im Holzbau. Proceedings Integrierter Umweltschutz im Bereich der Holzwirtschaft. Göttingen, München, pp 104-108

27. Xie Y, Fu Q, Wang Q, Xiao Z, Militz H (2013) Effects of chemical modification on the mechanical properties of wood. Eur J Wood Wood Prod 71(4):401-416

28. Peng Y, Han Y, Gardner DJ (2012) Southern pine impregnated with silicate solution containing cellulose nanofibrils. Holzforschung 66(6):735-737

\section{Submit your manuscript to a SpringerOpen ${ }^{\circ}$ journal and benefit from:}

- Convenient online submission

- Rigorous peer review

- Open access: articles freely available online

- High visibility within the field

- Retaining the copyright to your article

Submit your next manuscript at $\boldsymbol{\text { springeropen.com }}$ 